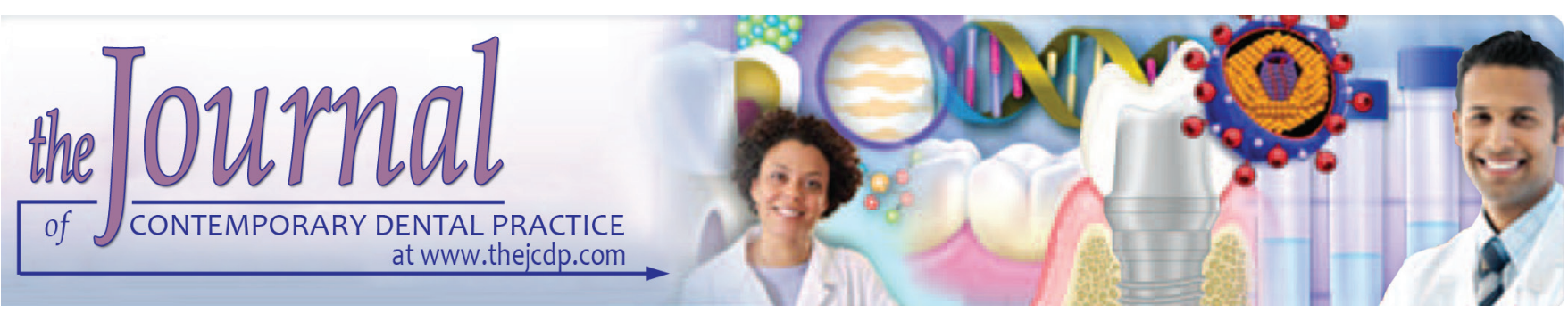

\title{
A Clinical and Microbiological Evaluation of Helicobacter pylori in Recurrent Aphthous Stomatitis
}

\author{
${ }^{1}$ Kamala Rajendra, ${ }^{2}$ Sadananda M Purnachandra, ${ }^{3}$ Parthkumar C Patel, ${ }^{4}$ Jochima Cota, ${ }^{5}$ Venkat R Singh, ${ }^{6}$ Ankur Vatsal
}

\begin{abstract}
Aim: The aim of this study is to evaluate the association of Helicobacter pylori in recurrent aphthous stomatitis (RAS) with or without peptic ulcer.
\end{abstract}

Materials and methods: A total of 42 patients were selected for the present study from outpatient Department of Oral Medicine, and divided into control (group I) and test groups (groups II, III). A total number of 15 patients suffering from RAS based on history and clinical examination was selected as group II. A total number of 12 patients suffering concomitantly from RAS and duodenal ulcer based on history and clinical examination were selected as group III. A total number of 15 healthy subjects were selected as controls in group I. All selected subjects belonged to the age group of 16 to 45 years. Data were tabulated and statistically analyzed with Statistical Package for the Social Sciences (SPSS) statistical software version 19 of IBM, Chicago, Illinois, USA.

Results: Among all three groups, $54.8 \%$ was negative and $45.2 \%$ was positive for $H$. pylori. No significant relation was established between $H$. pylori and RAS.

\footnotetext{
${ }^{1}$ Department of Oral Medicine \& Radiology, ESI-Post Graduate Institute of Medical Science \& Research, Bengaluru, Karnataka India

${ }^{2}$ Department of Oral and Maxillofacial Surgery, KGF College of Dental Sciences \& Hospital, Kolar Gold Fields, Karnataka, India

${ }^{3}$ Private Practitioner, Vadodara, Gujarat, India

${ }^{4}$ Department of Oral \& Maxillofacial Pathology and Forensic Dentistry, Betalbatim, Goa, India

${ }^{5}$ Department of Preventive \& Community Dentistry, Dental College, India

${ }^{6}$ Department of Public Health Dentistry, Institute of Dental Education \& Advance Studies (IDEAS), Gwalior, Madhya Pradesh, India

Corresponding Author: Kamala Rajendra, Department of Oral Medicine \& Radiology, ESI-Post Graduate Institute of Medical Science \& Research, Bengaluru, Karnataka, India, e-mail: drkamala81@gmail.com
}

Conclusion: In the present study, there was no association of $H$. pylori in patients with RAS and in patients with RAS along with gastric ulcers.

Clinical significance: This clinical study evaluated the relation of $H$. pylori in RAS patients.

Keywords: Aphthous stomatitis, Helicobacter pylori, Oral cavity, Pathogenesis.

How to cite this article: Rajendra K, Purnachandra SM, Patel PC, Cota J, Singh VR, Vatsal A. A Clinical and Microbiological Evaluation of Helicobacter pylori in Recurrent Aphthous Stomatitis. J Contemp Dent Pract 2017;18(12):1194-1197.

Source of support: Nil

Conflict of interest: None

\section{INTRODUCTION}

Recurrent aphthous stomatitis is an inflammatory ulcerative disorder of oral mucosa. ${ }^{1-3}$ In general, these patients have eating and speaking problems. ${ }^{2}$ Pathogenesis of RAS is related to genetic, immunological, microbial factors as well as local or systemic conditions. ${ }^{1,3,4}$ Since the characteristics of peptic ulcers and oral aphthous ulcers have histological similarities, it was believed that development of RAS could be due to H. pylori. ${ }^{1-4}$

The person infected with $H$. pylori can be an asymptomatic carrier. ${ }^{1}$ Helicobacter pylori is a Gram-negative, microaerophilic, spiral-shaped bacteria found in the mucosa of the gastric region. ${ }^{1,2,5}$ Infection of $H$. pylori is serious, transmissible, and associated with peptic and duodenal ulcers, gastric carcinoma, and non-Hodgkin's lymphomas of gastric mucosa related with lymphoid tissue. It has been observed from the earlier studies that these bacteria infected 20 to $30 \%$ of adult people in developed countries and more than $90 \%$ of them in the developing countries. Helicobacter pylori is mostly found in contaminated foods, feces, saliva, and the dental plaque of healthy individuals, and also in patients with upper digestive system disease. This infection can be 
caused through oral (plaque), fecal-oral, or gastrooral through gastrointestinal refluxes. ${ }^{1}$ Helicobacter pylori can be present in both genders of different ages, races, and geographic areas.

Based on ulcer size and number, RAS is classified as minor, major, and herpetiform. ${ }^{1,2}$ High prevalence of $H$. pylori was detected in patients with poor oral hygiene and with periodontal problems with pockets, plaque, and gingival bleeding. ${ }^{5}$ There are limited data regarding the relevancy of RAS and H. pylori infection. Hence, this study was undertaken to comparatively evaluate the association of H. pylori in RAS and in patients with peptic ulcer.

\section{MATERIALS AND METHODS}

A total of 42 patients were selected for the present study from the outpatient Department of Oral Medicine and divided into control (group I) and test groups (groups II, II). A total number of 15 patients suffering from RAS based on history and clinical examination were selected as group II. A total number of 12 patients suffering concomitantly from RAS and duodenal ulcer based on history and clinical examination were selected as group III. A total number of 15 healthy subjects were selected as controls (group I). The ages of the subjects were from 16 to 45 years. Inclusion criteria were as follows: Control group I included subjects without any history of aphthous ulcers, duodenal ulcers, and no history of any systemic diseases or systemic medications, study group II included subjects with RAS and without a history of duodenal ulcers, and group III included subjects with recurrent aphthous ulcers with associated duodenal ulcers. Exclusion criteria were as follows: Subjects using oral rinses, on systemic medication, presence of any local, or systemic diseases.

An ethical clearance was obtained from the Ethical Committee of the college, and informed consent was obtained from participant subjects. A detailed case history with emphasis on the history of past ulcers was taken on standard performance. A detailed clinical examination was carried out.

\section{Method of Sample Collection}

In the study groups, mucosal swab from the oral lesion was taken from study subjects with RAS before the 3rd day of the symptoms. Lesions with clear margins and surrounded by an erythematous halo was selected. For control groups, the swabs were taken from any one of the oral sites, such as tongue, labial mucosa, and floor of the mouth. Sterile plastic tips were used to collect the swab sample and placed immediately in Krebs buffer solution ( $\mathrm{NaCl} 20 \%, \mathrm{KCl} 2 \% \mathrm{CaCl}_{2} \cdot 2 \mathrm{H}_{2} \mathrm{O} 2 \%, \mathrm{MgSO}_{4}, \mathrm{KH}_{2} \mathrm{PO}_{4}$, and $\mathrm{C}_{6} \mathrm{H}_{12} \mathrm{O}_{6}$ ).
Sample is submitted to the laboratory for $H$. pylori deoxyribonucleic acid (DNA) isolation using nested polymerase chain reaction (PCR) method. Nested PCR oligonucleotide primers were constructed for a characterized DNA sequence of $H$. pylori. Specific outer and inner primers were selected for PCR using the Mac Vector program based on annealing temperature and size of fragments. The PCR was performed using Taq polymerase. The first routine amplification was performed with a single primer pair. Data were tabulated and statistically analyzed with the SPSS statistical software version 19 of IBM, Chicago Illinois, USA.

\section{RESULTS}

The majority of the subjects were males in groups I and II, while in group II, it was females (Graph 1). The mean age distribution was 16 to 45 years.

Out of the total 42 subjects in the study, 19 (45.2\%) were positive and $23(54.8 \%)$ were negative for $H$. pylori. In group I, $7.1 \%$ were positive and $28.6 \%$ were negative, and in group II, $21.4 \%$ were positive and $14.3 \%$ were negative for $H$. pylori. In group III, $16.7 \%$ were positive and $11.9 \%$ were negative for $H$. pylori (Table 1 ).

When oral carriage of $H$. pylori was compared between control and study groups, the majority were negative for H. pylori (Table 2, Graph 2). When comparison was made

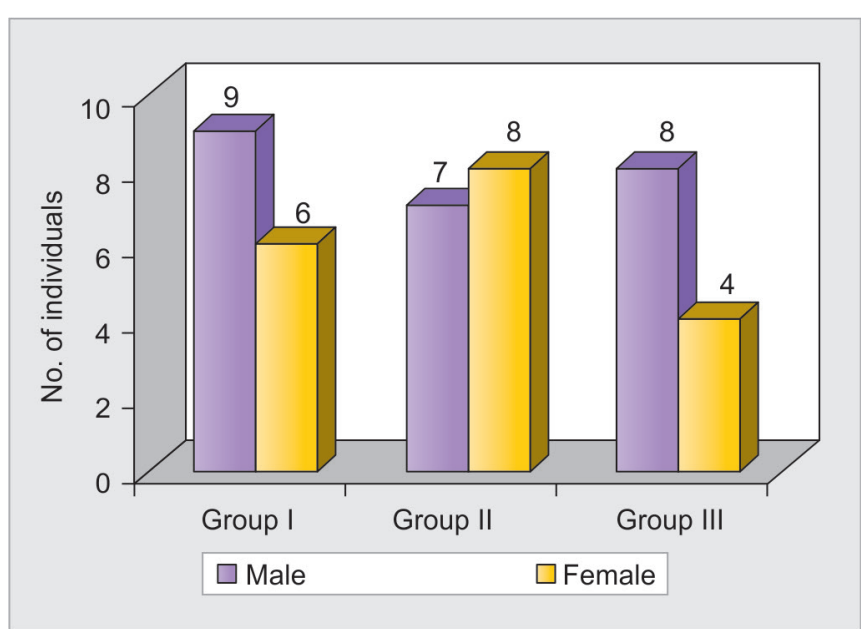

Graph 1: Gender distribution within the study groups II, III and control group I

Table 1: Oral carriage of $H$. pylori in the study groups II, III and control group I

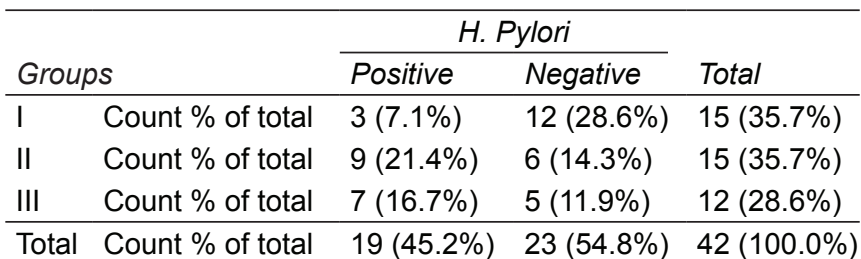

$\chi^{2}=6.007 ; p$-value $=.056 ; \chi^{2}=2.868 ; p$-value $=.580$ 
Table 2: Comparison of oral carriage of $H$. pylori between control groups I and II

\begin{tabular}{lllll}
\hline & & \multicolumn{2}{c}{ H. Pylori } & \\
\cline { 2 - 4 } Groups & Positive & Negative & Total \\
\hline I & Count $\%$ of total & $3(10.0 \%)$ & $12(40.0 \%)$ & $15(50.0 \%)$ \\
II & Count $\%$ of total & $9(30.0 \%)$ & $6(20.0 \%)$ & $15(50.0 \%)$ \\
\hline Total & Count \% of total & $12(40.0 \%)$ & $18(60.0 \%)$ & $30(100.0 \%)$ \\
\hline
\end{tabular}

Fishers exact test $p$-value $=0.060 \mathrm{~ns}$

between groups II and III, 59.3\% were positive and 40.7\% were negative for $H$. pylori (Graph 3).

\section{DISCUSSION}

It has been observed that $H$. pylori plays a major role development of ulcerative disease of the upper digestive system. ${ }^{6}$ The etiology of RAS until date remains unclear. Autoimmunity mechanism or genetic factors has been considered to play a role in the pathogenesis of RAS. However, $5 \%$ of the cases are said to be relevant with gastrointestinal disease. ${ }^{7}$ The mechanism for tissue injury by $H$. pylori is not clear. Immune-mediated mechanisms induced by $H$. pylori strains have the ability to stimulate cytokine production, particularly, interleukin- 8 and to induce the secretion of lymphocytic chemotactic factors with the formation of T lymphocyte. ${ }^{6}$

The present study investigated the association of H. pylori in patients with RAS and also in patients with RAS and concomitant duodenal ulcers using nested PCR method. For this study, subjects between 16 and 45 years of age groups were selected. In control group I, 15 healthy subjects without any sign and symptoms of RAS and duodenal ulcers were selected. A total of 27 patients with a history of RAS and/or duodenal ulcers were selected. Most of the patients in our study were young, with $60 \%$ being in the age group of 20 to 25 years. Similar findings were reported by Scully et al

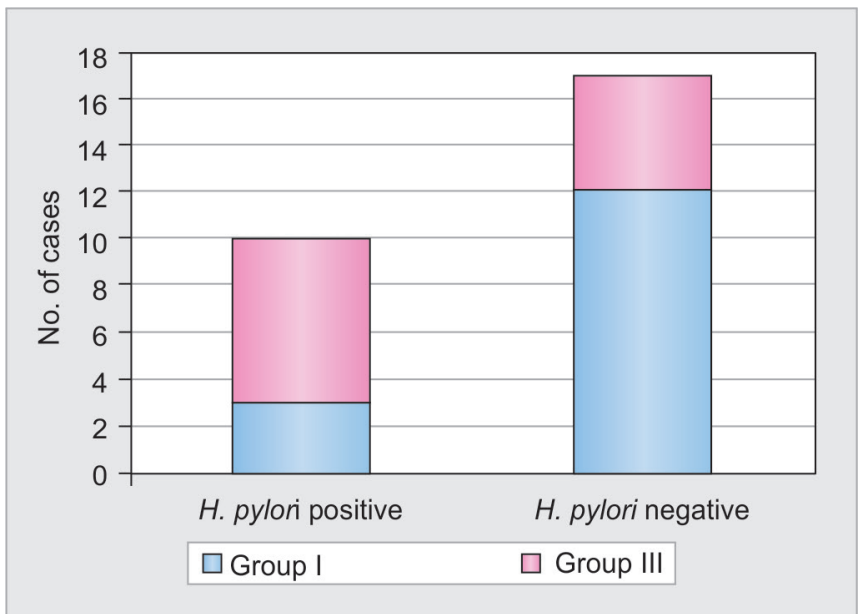

Graph 2: Comparison of oral carriage of $H$. pylori between the groups III and I who stated that before 30 years of age, $80 \%$ of patients develop RAS condition. ${ }^{8}$

Out of the total 27 patients in the study groups II and III, the study consisted of 12 female and 15 male patients. We observed a higher prevalence of RAS in males than in females. Sun et al reported similar findings in which males were predominantly affected. ${ }^{9}$ However, in the present study, gender distribution could be attributed to the sample size, which mainly comprised males.

All our study group II and III patients had minor aphthous stomatitis. The literature suggests that minor aphthous stomatitis is the most common form of RAS. ${ }^{10,11}$ Out of the total 27 patients in the study groups II and III, 12 patients had a recurrence of ulcers every 15 days to 1 month, 8 had recurrence every 1 to 2 months, and 7 patients had recurrence every 2 to 3 months. The findings of this study show that frequency of recurrence of ulcers was more in between 1 and 2 months, which is in accordance with the study carried out by Ship et al. ${ }^{12}$

The present study investigated the association of $H$. pylori in patients with only RAS (study group II) and compared with healthy control group I subjects. Out of the total 42 subjects in the study, 19 ( $45.2 \%)$ were positive and $23(54.8 \%)$ were negative for $H$. pylori (Table 1$)$. The results of the study demonstrated that the identification of H. pylori in RAS lesions (9 of 15) was clinically significant, but was not of statistical significance when correlated with the normal control subjects ( 3 of 15; Table 2). The findings of the present study are in accordance with the studies carried out by Mravak-Stipetic et al and Riggi et al, which have not identified a definite association between H. pylori and RAS. ${ }^{13,14}$ There was a notable clinical significance, but it was not statistically significant. The PCR assay mentioned in our study has been shown to be very sensitive and specific because of the use of two sets of primers. ${ }^{15}$

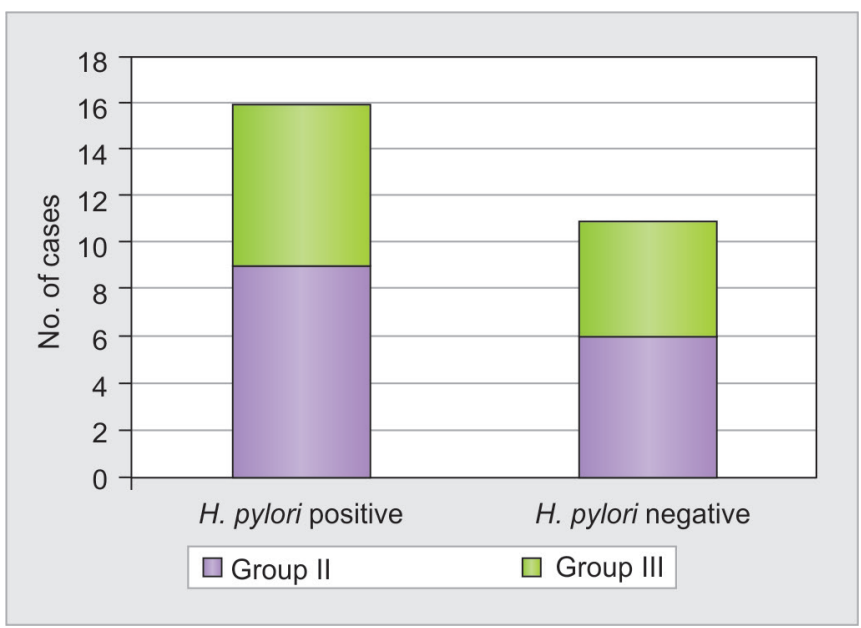

Graph 3: Comparison of oral carriage of $H$. pylori within the study groups II and III 
Similar to our results (Table 1), Afghari et al and Gomes et al observed from the systematic review that there was no correlation between H. pylori infection and RAS. ${ }^{1,4}$ Many researchers are in agreement with our results that there is no association of $H$. pylori in recurrent aphthous ulcer (from PCR and enzyme-linked immunosorbent assay tests), ${ }^{2,15}$ while Ding et al, from their study, concluded that $H$. pylori is significantly associated with periodontal diseases and caries. Yakar et al also concluded that $H$. pylori can be a predisposing factor for RAS. ${ }^{5}$

The present study reveals that the detection of $H$. pylori on RAS lesions in patients with duodenal ulcer was not statistically different from the normal control subjects. The study showed that five patients with gastroesophageal reflex disease (GERD) were positive for H. pylori and two patients without GERD were negative for $H$. pylori. It was observed that $H$. pylori is more common in patients with GERD and gastric ulcers than in patients with gastric ulcers without GERD. The findings are in accordance with the study carried out by Elsheikh and Mahfouz. ${ }^{16}$

We compared the association of $H$. pylori in patients only with RAS (study group II) and in patients with RAS and concomitant gastric ulcers (study group III), which did not reveal any statistical difference. In the present study, out of 15 healthy controls without a clinical history of RAS and concomitant gastric ulcers, 3 subjects were positive for $H$. pylori. Adler et al in a review hypothesized that oral microflora may be a permanent reservoir of $H$. pylori, which is still controversial and they stated that recovery of $H$. pylori in the mouth is probably intermittent, associated with GERD, but not with specific oral diseases. ${ }^{17}$ In contrast to our results, Elsheikh and Mahfouz observed association of $H$. pylori in RAS. ${ }^{16}$ However, in the present study, we could not determine the association of $H$. pylori in patients with RAS and in patients with RAS and concomitant gastric ulcers as the sample size was too small. Thus, further studies using large sample size and with the same clinical parameters need to be conducted.

\section{CONCLUSION}

The present study showed that there was no association of H. pylori in patients with RAS and in patients with RAS along with gastric ulcers.

\section{REFERENCES}

1. Afghari P, Khazaei S, Kazemi S, Savabi O, Keshteli AH, Adibi P. The role of Helicobacter pylori in the development of recurrent aphthous stomatitis: Sepahan systematic review no 9. Dent Res J (Isfahan) 2011 Dec;8(Suppl 1):S2-S8.
2. Mansour-Ghanaei F, Asmar M, Bagherzadeh AH, Ekbataninezhad S. Helicobacter pylori infection in oral lesions of patients with recurrent aphthous stomatitis. Med Sci Monit 2005 Dec;11(12):CR576-CR579.

3. Yakar T, Serin E, Cosar AM, Arslan Tas D, Ataç FB. The relationship of recurrent aphthous stomatitis and Helicobacter pylori, cytokine gene polymorphism and cobalamin. Turk J Gastroenterol 2015 Jul;26(4):304-308.

4. Gomes CC, Gomez RS, Zina LG, Amaral FR. Recurrent aphthous stomatitis and Helicobacter pylori. Med Oral Patol Oral Cir Bucal 2016 Mar;21(2):e187-e191.

5. Ding YJ, Yan TL, Hu XL, Liu JH, Yu CH, Li YM, Wang QY. Association of Salivary Helicobacter pylori infection with oral diseases: a cross-sectional study in a Chinese population. Int J Med Sci 2015 Sep;12(9):742-747.

6. White JR, Winter JA, Robinson K. Differential inflammatory response to Helicobacter pylori infection: etiology and clinical outcomes. J Inflamm Res 2015 Aug;8:137-147.

7. Field EA, Allan RB. Review article: oral ulcerationaetiopathogenesis, clinical diagnosis and management in the gastrointestinal clinic. Aliment Pharmacol Ther 2003 Aug;18(10): 949-962.

8. Scully C, Gorsky M, Lozada-Nur F. The diagnosis and management of recurrent aphthous stomatitis: a consensus approach. J Am Dent Assoc 2003 Feb;134(2):200-207.

9. Sun A, Chia JS, Chang YF, Chiang CP. Levamisole and Chinese medicinal herbs can modulate the serum interleukin-6 level in patients with recurrent aphthous ulcerations. J Oral Pathol Med 2003 Apr;32(4):206-214.

10. Ship JA. Recurrent aphthous stomatitis. an update. Oral Surg Oral Med Oral Pathol Oral Radiol Endod 1996 Feb;81(2): 141-147.

11. Victória JM, Kalapothakis E, Silva Jde F, Gomez RS. Helicobacter pylori DNA in recurrent aphthous stomatitis. J Oral Pathol Med 2003 Apr;32(4):219-223.

12. Ship II, Brightman VJ, Laster LL. The patient with recurrent aphthous ulcers and the patient with recurrent herpes labialis: a study of two population samples. J Am Dent Assoc 1967 Sep;75(3):645-654.

13. Mravak-Stipetić M, Gall-Troselj K, Lukac J, Kusić Z, Pavelić K, Pavelić J. Detection of Helicobacter pylori in various oral lesions by nested polymerase chain reaction (PCR). J Oral Pathol Med 1998 Jan;27(1):1-3.

14. Riggio MP, Lennon A, Wray D. Detection of Helicobacter pylori DNA in recurrent aphthous stomatitis tissue by PCR. J Oral Pathol Med 2000 Nov;29(10):507-513.

15. Fritscher AM, Cherubini K, Chies J, Dias AC. Association between Helicobacter pylori and recurrent aphthous stomatitis in children and adolescents. J Oral Pathol Med 2004 Mar;33(3):129-132.

16. Elsheikh MN, Mahfouz ME. Prevalence of Helicobacter pylori DNA in recurrent aphthous ulcerations in mucosa-associated lymphoid tissues of the pharynx. Arch Otolaryngol Head Neck Surg 2005 Sep;131(9):804-808.

17. Adler I, Muiño A, Aguas S, Harada L, Diaz M, Lence A, Labbrozzi M, Muiño JM, Elsner B, Avagnina A, et al. Helicobacter pylori and oral pathology: relationship with the gastric infection. World J Gastroenterol 2014 Aug;20(29):9922-9935. 